\title{
Bowl-Shaped Naphthalimide-Annulated Corannulene as Nonfullerene Acceptor in Organic Solar Cells
}

\author{
Kaan Menekse ${ }^{\ddagger a}$ \\ Rebecca Renner ${ }^{\dagger b}$ \\ Bernhard Mahlmeister ${ }^{a}$ \\ Matthias Stolte ${ }^{a, b}$ \\ Frank Würthner*a,b (iD \\ ${ }^{a}$ Center for Nanosystems Chemistry, Universität Würzburg, Theodor- \\ Boveri-Weg, 97074 Würzburg, Germany \\ ${ }^{\mathrm{b}}$ Institut für Organische Chemie, Universität Würzburg, \\ Am Hubland, 97074 Würzburg, Germany \\ wuerthner@uni-wuerzburg.de \\ ${ }^{\ddagger}$ Kaan Menekse and Rebecca Renner contributed equally to this work.
}

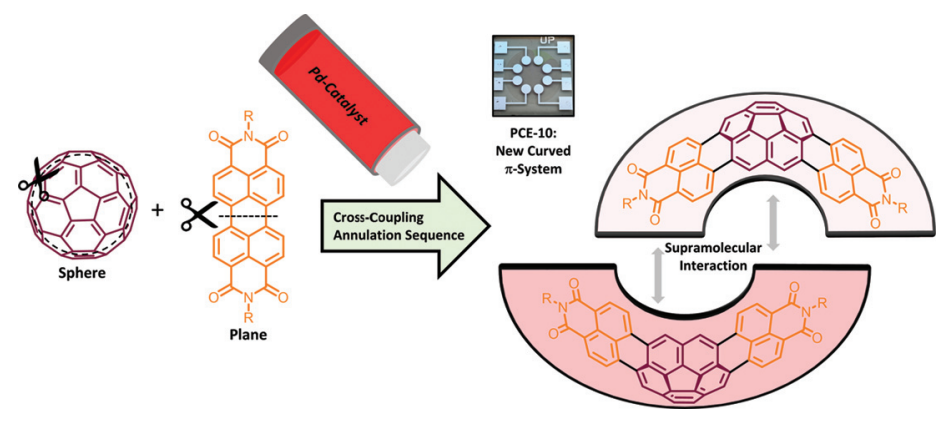

Received: 25.05.2020

Accepted after revision: 12.06 .2020

DOI: 10.1055/s-0040-1714283; Art ID: OM-20-0020sc

License terms: CCO

(c) 2020. The Author(s). This is an open access article published by Thieme under the terms of the Creative Commons Attribution-NonDerivative-NonCommercial-License, permitting copying and reproduction so long as the original work is given appropriate credit. Contents may not be used for commercial purposes, or adapted, remixed, transformed or built upon. (https://creativecommons.org/licenses/by-nc-nd/4.0/).

Abstract An electron-poor bowl-shaped naphthalimide-annulated corannulene with branched alkyl residues in the imide position was synthesized by a palladium-catalyzed cross-coupling annulation sequence. This dipolar compound exhibits strong absorption in the visible range along with a low-lying LUMO level at $-3.85 \mathrm{eV}$, enabling $n$-type charge transport in organic thin-film transistors. Furthermore, we processed inverted bulkheterojunction solar cells in combination with the two donor polymers PCE-10 and PM6 to achieve open-circuit voltages up to $1.04 \mathrm{~V}$. By using a blend of the self-assembled naphthalimide-annulated corannulene and PCE-10, we were able to obtain a power conversion efficiency of up to $2.1 \%$, which is to the best of our knowledge the highest reported value for a corannulene-based organic solar cell to date.

Key words corannulene, curved $\pi$-systems, bulk-heterojunction solar cells, nonfullerene acceptors, aggregation

\section{Introduction}

Nonplanar polycyclic aromatic hydrocarbons (PAHs) have started to gain more attention as alternative electron acceptor materials in organic electronics to replace fullerenes and their soluble derivatives. ${ }^{1-5}$ Due to their improved solubility compared to their planar PAH counterparts, along with the possibility to tune the electronic properties by substitution, these molecules are promising candidates for application in organic photovoltaics (OPVs). ${ }^{6,7}$ These nonplanar molecules are commonly implemented in bulk-heterojunction (BHJ) organic solar cells (OSCs) by derivatives of three-dimensional perylene bisimide architectures $^{8-10}$ or the bowl-shaped subphthalocyanine family. ${ }^{6,11,12}$

Corannulene, which is another example of bowl-shaped PAHs and a subunit of fullerene $\mathbf{C}_{\mathbf{6 0}}$, has been used in organic electronics, after the first synthesis in 1966 by Lawton and Barth, repeatedly. ${ }^{13,14}$ Its derivatives have been applied in organic field-effect transistors, ${ }^{15-17}$ organic light-emitting diodes, ${ }^{18,19}$ and nonlinear optics. ${ }^{20}$ Due to its structural similarity to fullerenes, which are still the state-of-the-art acceptor materials in OPVs, ${ }^{21}$ OSCs using corannulene and its derivatives have been fabricated by different groups. ${ }^{22}$ By substituting the phenyl group in the widely used phenyl- $\mathrm{C}_{61}$ butyric acid methyl ester $\left(\mathbf{P C}_{\mathbf{6 1}} \mathbf{B M}\right)$ with corannulene, a new fullerene-corannulene dyad has been successfully synthesized. This new molecule was implemented in a device using the donor polymer P3HT, resulting in a power conversion efficiency (PCE) of $1.05 \% .^{23}$ Furthermore, a series of decakis (arylthiol)corannulenes was used as electron-accepting materials, achieving the highest reported PCE for corannulene-based $\mathrm{BHJ}$ OSCs to date of $1.23 \%{ }^{24}$ The first reported example of a corannulene-based solar cell, however, utilizes a derivative, in which the electron-accepting abilities are enhanced by coupling the bowl-shaped PAH to either a phthalimide or a naphthalimide, respectively. By this means, Lu et al. were able to show a significant lowering of the LUMO level to $-3.24 \mathrm{eV}$ and better miscibility with P3HT compared to pristine corannulene, leading to a PCE of up to $1.03 \%{ }^{25}$

Recently, we reported the synthesis ${ }^{26}$ and self-assembly $^{27}$ of new dipolar naphthalimide-annulated corannulene (NAC) derivatives. Both, mono- and disubstituted NAC derivatives exhibit beneficial optoelectronic properties for use as nonfullerene acceptors (NFAs) in OSCs, such as the broad absorption between 400 and $600 \mathrm{~nm}$ and a low-lying LUMO level of $-3.88 \mathrm{eV}$. The so-far introduced residues in the imide position, 2,6-diisopropylphenyl (Dipp) and 3,4,5tris(dodecyl)phenyl (TDP), proved to be less suitable to the use in OSCs due to the extensive inactive alkyl content of the latter and the prevention of intimate $\pi-\pi$ interactions and 
thus suboptimal charge transport of the former. Thus, we decided to synthesize a new derivative, which combines the optoelectronic advantages of the double-NAC motif with high solubility and proper aggregation properties. By introduction of a branched alkyl chain, the desired solubility could be maintained and the new material was successfully implemented as a NFA in inverted BHJ OSCs.

\section{Results and Discussion}

Corannulene derivative $\mathbf{4}$ was synthesized according to Scheme 1 by a palladium-catalyzed Suzuki cross-coupling using tri( $m$-tolyl)phosphine as a ligand followed by a Hecktype annulation reaction using tri(1-adamantyl)phosphine as a ligand at a significantly higher temperature of $170{ }^{\circ} \mathrm{C}$, as reported previously, to enable the annulation reaction. ${ }^{25,26}$ By applying this sequential two-step synthesis, ${ }^{28}$ it was possible to obtain 4 in an adequate yield of $41 \%$ to get a sufficient amount of highly soluble material for the use in OSCs. In toluene, up to $51 \mathrm{mg} \mathrm{mL}^{-1}$ could be dissolved.

The new derivative was characterized using nuclear magnetic resonance spectroscopy and high-resolution mass spectrometry. The optical properties were measured by using UV/Vis and fluorescence spectroscopy in dichloromethane solution, to avoid any possible aggregation, similar to a previously reported derivative ${ }^{26}$ (Figure 1 , for details see the Supporting Information). The absorption maximum is observed at $503 \mathrm{~nm}$ with an extinction coefficient of $44,600 \mathrm{M}^{-1} \mathrm{~cm}^{-1}$ (Table S1). Due to the electron-poor naphthalimide annulation of the electron-rich corannulene core, which leads to an extension of the $\pi$-system, the absorption is significantly red-shifted compared to the

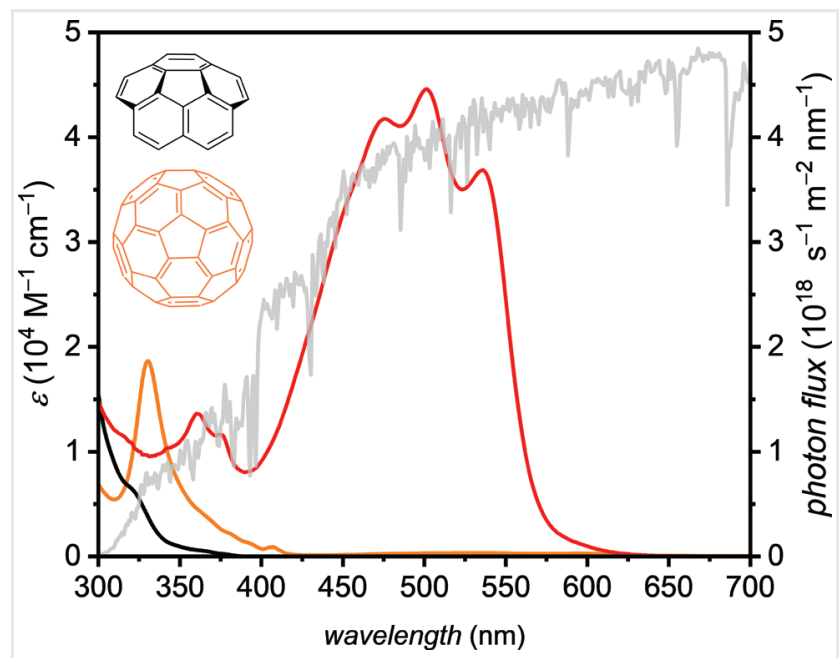

Figure $1 \mathrm{UV} / \mathrm{Vis}$ absorption spectra of $\mathbf{C}_{\mathbf{6 0}}$ (orange), corannulene (black), and the new corannulene derivative 4 (red) at $10^{-5} \mathrm{M}$ in $\mathrm{CH}_{2} \mathrm{Cl}_{2}$ in comparison to solar photon flux under AM 1.5G conditions (grey).

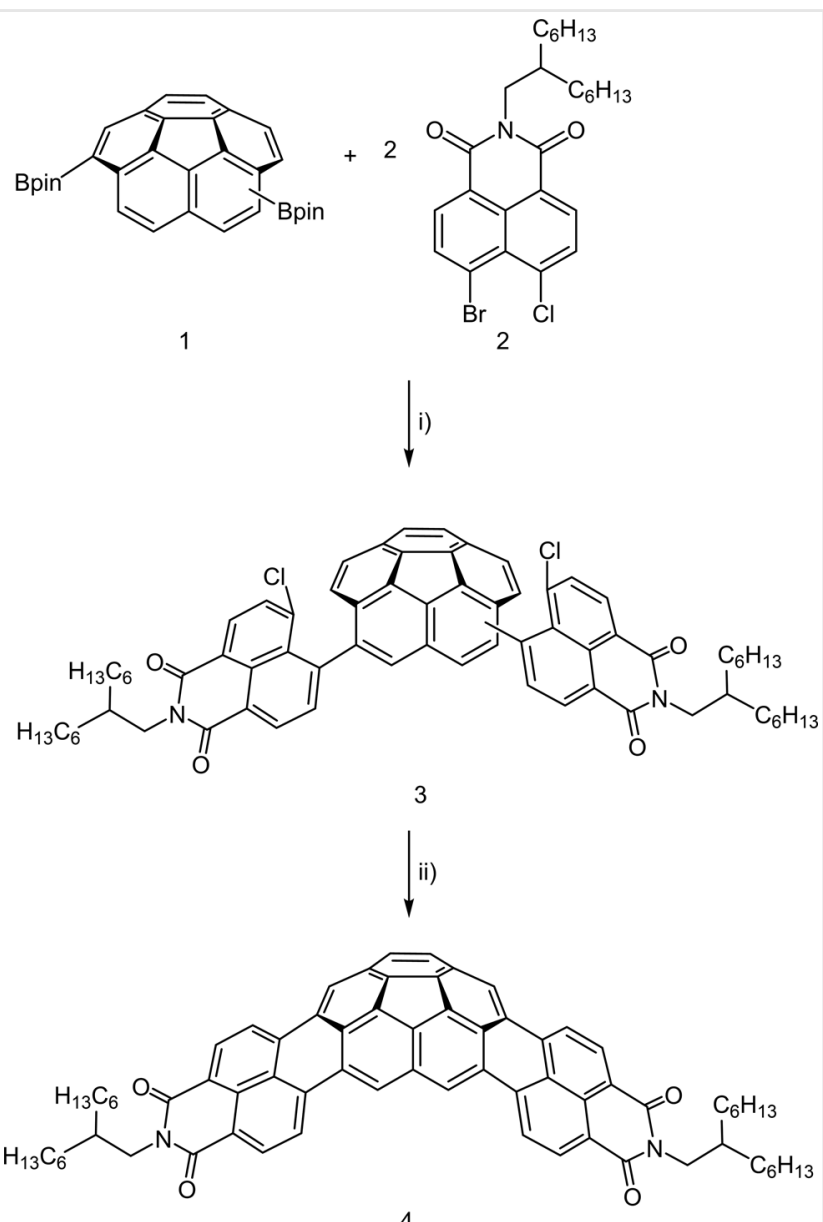

4

Scheme 1 Synthetic scheme for corannulene derivative 4: (i) $\left[\mathrm{Pd}_{2}(\mathrm{dba})_{3}\right] \cdot \mathrm{CHCl}_{3}, \mathrm{P}(\mathrm{m} \text {-tolyl })_{3}, \mathrm{Cs}_{2} \mathrm{CO}_{3}, 1$-chloronaphthalene, $110{ }^{\circ} \mathrm{C}, 2 \mathrm{~d}$; (ii) $\left[\mathrm{Pd}_{2}(\mathrm{dba})_{3}\right] \cdot \mathrm{CHCl}_{3}, \mathrm{PAd}_{3}, \mathrm{Cs}_{2} \mathrm{CO}_{3}, \mathrm{Bu}_{4} \mathrm{NCl}, 1$-chloronaphthalene, $170{ }^{\circ} \mathrm{C}$, $16 \mathrm{~h}$. Detailed synthetic procedures are reported in the Supporting Information.

parent corannulene and Suzuki-coupled derivatives, ${ }^{24}$ as well as the monoannulated derivative. ${ }^{25}$ Even more important is the huge increase in absorptivity with respect to the benchmark acceptor $\mathbf{C}_{\mathbf{6 0}}$, which should augment the lightharvesting ability in an OSC (Figure 1). The optical band gap was estimated to be $2.17 \mathrm{eV}$ from the onset of the absorption band in solution. The emission maximum at $572 \mathrm{~nm}$ as well as the fluorescence quantum yield of $46 \%$ and fluorescence lifetime of 5.19 ns are also in good accordance with previously reported values for the Dipp derivative, given the fact that the imide substituent has only minor impact on optoelectronic properties but influences the solubility, self-assembly, as well as the solid-state packing (Table S1). Further studies of the self-assembly of the new derivative 4 by UV/Vis spectroscopy in toluene revealed the ability to form defined aggregates in this aromatic solvent at high concentrations (Figure S1). The process could be ascribed to an anticooperative nucleation- 

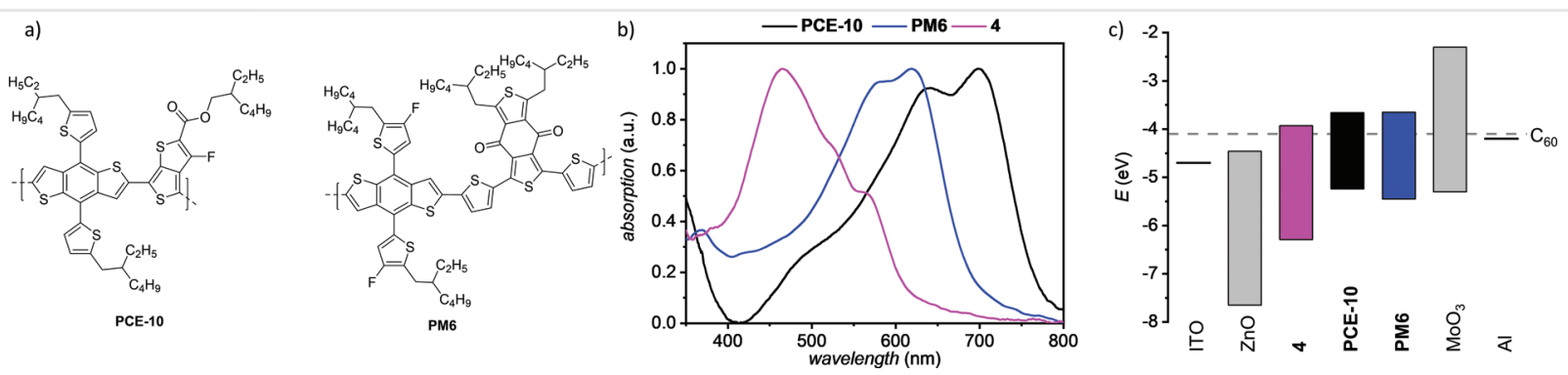

Figure 2 (a) Chemical structures of donor polymers PCE-10 and PM6. (b) Normalized UV/Vis spectra of spin-coated thin films of donor polymers PCE-10 (black), PM6 (blue) and corannulene derivative 4 (pink) on quartz (chlorobenzene, $7.5 \mathrm{mg} \mathrm{mL}^{-1}$ ). (c) Schematic diagram of the electrical band gaps for all materials used in OPV experiments. The $E_{\mathrm{LUMO}}$ of fullerene $\mathbf{C}_{\mathbf{6 0}}$ is given as reference $(-4.1 \mathrm{eV})$.

elongation mechanism of $\mathbf{4}$, where the formation of dimers is highly favored over the formation of extended structures. In toluene, the application of the $K_{2}-K$ aggregation model ${ }^{29}$ using a nucleus size of two gave $K=6.5 \times 10^{2} \mathrm{M}^{-1}$, $K_{2}=5.2 \times 10^{3} \mathrm{M}^{-1}$, and a cooperativity factor $\sigma=8$, indicating only slightly lower tendency to aggregate compared to the previously reported TDP system. ${ }^{27}$ This preorganization into well-defined small-aggregate entities with high tinctorial strength and electron affinity in solution will affect the morphology of thin films and efficiency as a NFA in OPV (vide infra).

The optical signature of the spin-cast thin film of $\mathbf{4}$ on quartz (Figure $2 \mathrm{~b}$ ) resembles the hypsochromically shifted features of aggregated NAC chromophores with an absorption maximum at about $465 \mathrm{~nm}$ of the previously investigated NAC dimer species in solution (Figure S2). ${ }^{27}$ However, this hypsochromically shifted absorption of $\mathbf{4}$ in the thin film enables excellent complementary absorption of solar light with the most common donor polymers in the visible up to the near-infrared spectral region (Figure 2a,b). The donor polymer PM6 absorbs light in the range from 570 to $700 \mathrm{~nm}$. PCE-10 shows an even more bathochromically shifted absorption in comparison to PM6 up to $800 \mathrm{~nm}$. The electrochemical properties were characterized by cyclic and square wave voltammetry in dichloromethane (Figure S9). The molecule showed three reversible reduction processes, of which the first two could not be observed completely separated at approximately $-1.25,-1.37$, and $-1.74 \mathrm{~V}$, and two irreversible oxidation processes at 1.00 and $1.24 \mathrm{~V}$. The HOMO and LUMO energy levels were calculated to be at -6.10 and $-3.85 \mathrm{eV}$, respectively, according to the assumption that the energy level of the $\mathrm{Fc} / \mathrm{Fc}^{+}$redox couple is $-5.1 \mathrm{eV}$ relative to vacuum. ${ }^{30}$ With this the prerequisites for the use of the new compound as a NFA in OSC are given. Additionally, the LUMO level of $\mathbf{4}$ is also comparable to that of commonly used $\mathbf{P C}_{\mathbf{6 1}} \mathbf{B M}$. Due to a slightly higher LUMO level for $\mathbf{4}$ compared with $\mathbf{P C}_{\mathbf{6 1}} \mathbf{B M}$, higher open-circuit voltages $\left(V_{\mathrm{OC}}\right)$ are expected. Solution-processed solar cells based on PCE-10 and PM6 (Figure 2c) demonstrate the influence of the HOMO of the donor polymer to the opencircuit voltage, due to their difference in $E_{\text {Номо }}$ and the resultant gap to the LUMO level of the acceptor of $1.4 \mathrm{eV}$ (PCE-10) and 1.6 eV (PM6), respectively. The photovoltaic properties were investigated under optimized conditions in an inverted device architecture (ITO/ZnO/Polymer:4/ $/ \mathrm{MoO}_{3} /$ $\mathrm{Al}) .^{31}$ The architecture of the OSC, the representative $J-V$ curves, as well as the UV/Vis and external quantum efficiency (EQE) spectra for the best-performing devices
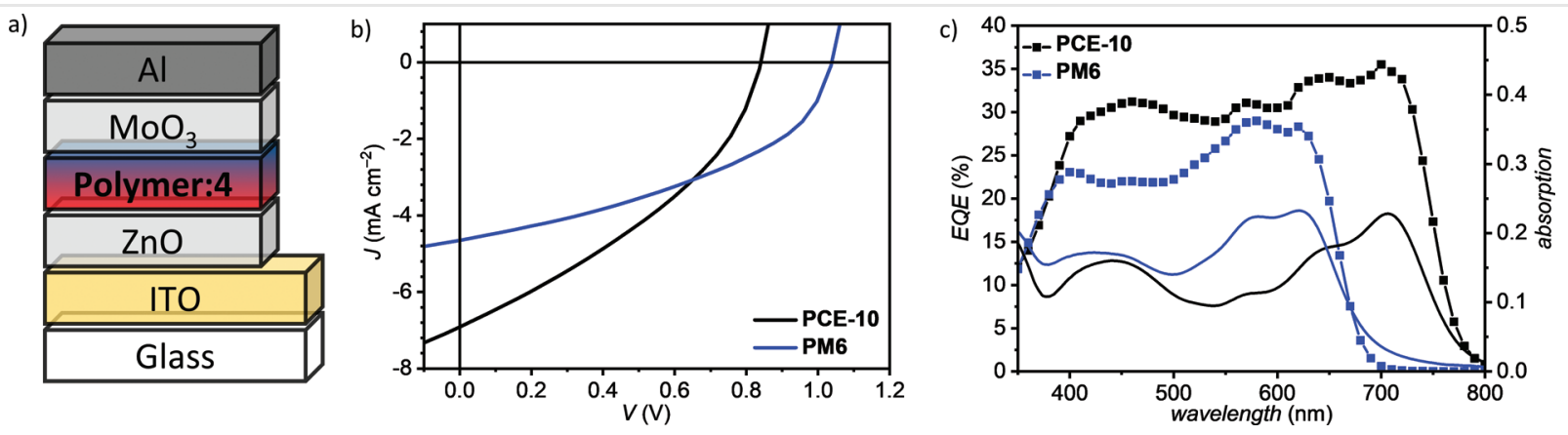

Figure 3 (a) Device architecture of inverted BHJ OSC. (b) J-V curves of ITO/ZnO (30 nm)/BHJ/MoO $(10 \mathrm{~nm}) / \mathrm{Al}(100 \mathrm{~nm})$ of NAC 4 in 1:1 ratio with donor polymers PCE-10 (black) and PM6 (blue) measured under inert conditions and under AM 1.5G irradiation. (c) EQE (symbols) and UV/Vis (solid lines) spectra of polymer: 4 based OSC. 
Table 1 Photovoltaic parameters of OSCs based on $\mathbf{4}$ in combination with donor polymers PCE-10 and PM6 in 1:1 ratio in the architecture $\mathrm{ITO} / \mathrm{ZnO} / \mathrm{BHJ} / \mathrm{MoO}_{3} / \mathrm{Al}$

\begin{tabular}{llllll}
\hline Donor & $J_{\mathrm{SC}}\left(\mathrm{mA} \mathrm{cm}^{-2}\right)$ & $V_{\mathrm{OC}}(\mathrm{V})$ & $\mathrm{FF}(\%)$ & $\mathrm{PCE}(\%)$ & PCE $_{\max }(\%)$ \\
\hline PCE-10 $^{\mathrm{a}}$ & $-6.71 \pm 0.1$ & $0.82 \pm 0.02$ & $36 \pm 1$ & $2.0 \pm 0.1$ & 2.1 \\
PM6 $^{\mathrm{a}}$ & $-4.52 \pm 0.2$ & $1.02 \pm 0.02$ & $40 \pm 2$ & $1.9 \pm 0.1$ & 2.0 \\
\hline
\end{tabular}

${ }^{a}$ Average of at least seven independent devices.

are depicted in Figure 3. The photovoltaic parameters are listed in detail in Table 1.

We optimized the processing parameters of the total concentration, donor-acceptor ratio, and additives for the PCE-10:4 based OPV (Figures S10, S11, S12) to achieve the highest so-far reported PCE of a corannulene-based NFA of up to $2.1 \%$. The best-performing blend for processing the active layer with a thickness of about $60 \mathrm{~nm}$ was prepared by dissolving the polymers $\left(7.5 \mathrm{mg} \mathrm{mL}^{-1}\right)$ in chlorobenzene followed by mixing with 4 in a $1: 1$ ratio. All steps were performed under inert conditions. This blend solution was spin-cast without additives at $1000 \mathrm{rpm}$ for $60 \mathrm{~s}$ on a freshly prepared ITO/ZnO substrate, without any further treatment by thermal or solvent-vapor annealing. The devices were completed by thermal evaporation of $10 \mathrm{~nm} \mathrm{MoO}_{3}$ as a hole-transporting layer as well as a $100 \mathrm{~nm}$ aluminum electrode and measured under AM 1.5G irradiation. The OSCs showed maximum PCEs of 2.1\% (PCE-10) and 2.0\% (PM6), respectively. While OSCs of PCE-10 exhibit a 33\% higher short-circuit current density $\left(J_{\mathrm{sc}}\right)$ of $-6.71 \mathrm{~mA} \mathrm{~cm}^{-2}$, devices based on PM6 compensate this deficiency by a 25\% increase in the $V_{\mathrm{OC}}$ value up to $1.04 \mathrm{eV}$. In comparison to devices processed under identical conditions with the unsubstituted corannulene, the OPV performance was significantly enhanced for our new annulated derivative (Figures S13 and S14; Table S2). This is caused by a tenfold higher $J_{\mathrm{SC}}$ value due to the significantly shifted strong absorption of $\mathbf{4}$ in the visible region. Additionally, a higher $V_{\mathrm{OC}}$ due to better energetic alignment of $\mathbf{4}$ with the donor polymer could be realized. However, for all OSCs using PCE-10, only moderate fill factors (FFs) could be achieved.

The PCE-10:4 based OSC generates a higher $J_{S C}$ of $-6.71 \mathrm{~mA} \mathrm{~cm}^{-2}$ compared to the PM6:4 based OSC, which exhibits a $J_{\mathrm{SC}}$ of $-4.52 \mathrm{~mA} \mathrm{~cm}{ }^{-2}$. This is attributed to the more bathochromically shifted absorption of PCE-10 in comparison to PM6, enabling more light accumulation (Figure 2b). The contribution of PCE-10 and $\mathbf{4}$ to the photocurrent of the solar cell could be determined by comparing both EQE and UV/Vis spectra of the PCE-10:4 based OSC (Figure 3c). The highest photocurrent in the range from 400 to $550 \mathrm{~nm}$ is mainly generated by 4 , while above $550 \mathrm{~nm}$ it originates solely from PCE-10. The OPV shows a continuous high EQE over $30 \%$ in a broad spectral range from 400 to $720 \mathrm{~nm}$. The highest EQE was observed in the range of the PCE-10 of 35\%. Due to the stronger overlap of the absorption of PM6 and 4, the generated short-circuit current density and the EQE are lower. The calculated $J_{S C}$ values, which were obtained by the integration of the EQE, are -4.28 and $-7.35 \mathrm{~mA} \mathrm{~cm}^{-2}$ for the PM6:4 and PCE-10:4 cells, respectively, and are in accordance with the $J-V$ measurements. Furthermore, both OSCs exhibit a continuous high EQE due to the absorption of 4, which perfectly fits in the absorption window between the two absorption peaks of both polymers. The similar efficiency of the PM6:4 OSCs originates from an increased open-circuit voltage of up to $1.04 \mathrm{~V}$, which is caused by the larger HOMO (donor)LUMO (acceptor) gap of about $1.6 \mathrm{eV}$. In contrast, the PCE-10:4 based OSC exhibits a $V_{\mathrm{OC}}$ of $0.84 \mathrm{~V}$ and a HOMO (donor)-LUMO (acceptor) gap of about $1.4 \mathrm{eV}$. Both OSCs showed the same energy loss factors $\left(E_{\text {loss }}\right)$ of about $0.6 \mathrm{~V}$, which is in good accordance with other corannulene-based OSCs. ${ }^{23,24}$ The moderate FFs, which are an indicator for an unbalanced charge transport (36\% for PCE-10:4 and 40\% for PM6:4), for both OSCs are the limiting OPV parameter. This seems to be mainly caused by the poor electron mobility of 4, which was further characterized in organic thin-film transistors (OTFTs). ${ }^{32}$ Annealed solution-processed thin films (5 min at $100{ }^{\circ} \mathrm{C}$ ) of $\mathbf{4}$ on OTES-treated $\mathrm{Si} / \mathrm{SiO}_{2}$ substrates only exhibit a modest $n$-type field-effect mobility of $10^{-5} \mathrm{~cm}^{2} \mathrm{~V}^{-1} \mathrm{~s}^{-1}$, a threshold voltage of $14 \mathrm{~V}$, and an $I_{\mathrm{on}} /$ $I_{\text {off }}$ ratio of $10^{2}$ in bottom-gate top-contact OTFT (transfer and output characteristics in Figures S15 and S16). Accordingly, we deduce from AFM images of the thin film of 4 on OTES-treated $\mathrm{Si} / \mathrm{SiO}_{2}$ substrates (Figure $\mathrm{S} 17$ ) that also compound 4 tends to aggregate in an anticooperative fashion without the formation of an extended aggregate domain under the investigated conditions, due to cancellation of the molecular dipole moments upon dimer formation. ${ }^{33}$ As this low-crystalline thin film is composed of randomly arranged dimers of $\mathbf{4}$, this might explain the rather poor performance in OTFTs. This assumption is corroborated by the AFM images of blend films of PCE-10:4 and PM6:4 (Figure 4), which exhibit spherical particles that form a homogenous surface. The PCE-10:4 active-layer morphology showed a root mean square $\left(R_{\mathrm{q}}\right)$ of $0.8 \mathrm{~nm}$ and

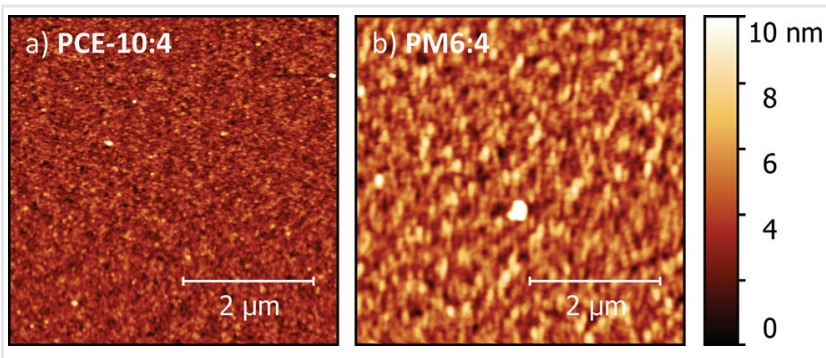

Figure 4 AFM height images of active layers of 4 in 1:1 ratio with PCE10 (a) and PM6 (b) of inverted BHJ OSCs on ITO/ZnO $\left(5 \times 5 \mu \mathrm{m}^{2}\right)$. 
for the PM6:4 based OSC the $R_{\mathrm{q}}$ value was increased to $1.4 \mathrm{~nm}$

As we could prove that prior to the spin-coating already a preorganization of $\mathbf{4}$ into dimers takes place in chlorobenzene solution (Figure S2), we assume that these dimer agglomerates were spin-coated on the substrate from the donor-acceptor blend. Due to the absence of higher aggregates, homogenous thin films with low $R_{\mathrm{q}}$ values are formed. This leads to a good blending into small domains of donor and acceptor, which can explain the high open-circuit voltage and the low energy loss factor. However, due to the low electron mobility of the NAC dimer in contrast to the used donor polymers, the FF decreases and probably recombination takes place. In accordance with the earlier examples, also the preorganized dimers of $\mathbf{4}$ give rise to only moderate FFs, presumably due to unbalanced charge transport. However, $V_{\mathrm{OC}}$ could be significantly increased up to 1.04 V (PM6:4) for our new NFA, due to a larger HOMO (donor)-LUMO (acceptor) gap and $J_{\mathrm{SC}}$ was increased up to $-6.71 \mathrm{~mA} \mathrm{~cm} \mathrm{~cm}^{-2}$ (PCE-10:4) due to the better interplay of the absorption properties between the donor and our new NFA 4.

\section{Conclusions}

In conclusion, a new electron-poor NAC derivative $\mathbf{4}$ was synthesized which inherits good solubility due to the curved $\pi$-system along with the two branched imide substituents. The molecule exhibits a low-lying LUMO level of $-3.85 \mathrm{eV}$ similar to fullerene $\mathbf{C}_{\mathbf{6 0}}$, but a much broader and more intense absorption in the visible range than the fullerene. This new NFA 4 self-assembles in an anticooperative fashion into dimer aggregates in the blend solutions with two different donor polymers and was successfully implemented in inverted BHJ OSCs. The best-performing blend was identified as a 1:1 mixture of $\mathbf{4}$ and PCE-10, which showed a maximum PCE of 2.1\%, while with PM6 a PCE of $2.0 \%$ with $V_{\mathrm{OC}}$ up to $1.04 \mathrm{~V}$ could be achieved. This is to the best of our knowledge the highest reported value for a corannulene-based NFA in OSCs.

\section{Funding Information}

We are grateful for financial support from the Deutsche Forschungsgemeinschaft (Grant Wu 317/20-1) as well as the Bavarian Research Program "Solar Technologies Go Hybrid".

\section{Acknowledgment}

We thank Dr. Kazutaka Shoyama (Würzburg) for his advice on the synthesis.

\section{Supporting Information}

Supporting information for this article is available online at http://doi.org/10.1055/s-0040-1714283.

\section{References}

(1) Ma, Z.; Winands, T.; Liang, N.; Meng, D.; Jiang, W.; Doltsinis, N. L.; Wang, Z. Sci. China Chem. 2020, 63, 208.

(2) Wang, X.-Y.; Yao, X.; Müllen, K. Sci. China Chem. 2019, 62, 1099.

(3) Wu, Y.-T.; Siegel, J. S. Chem. Rev. 2006, 106, 4843.

(4) Duan, C.; Zango, G.; García Iglesias, M.; Colberts, F. J.M.; Wienk, M. M.; Martínez-Díaz, M. V.; Janssen, R. A.J.; Torres, T. Angew. Chem. Int. Ed. 2017, 56, 148.

(5) Magiera, K. M.; Aryal, V.; Chalifoux, W. A. Org. Biomol. Chem. 2020, 18, 2372.

(6) Meng, D.; Liu, G.; Xiao, C.; Shi, Y.; Zhang, L.; Jiang, L.; Baldridge, K. K.; Li, Y.; Siegel, J. S.; Wang, Z. J. Am. Chem. Soc. 2019, 141, 5402.

(7) Huang, X.; Hu, M.; Zhao, X.; Li, C.; Yuan, Z.; Liu, X.; Cai, C.; Zhang, Y.; Hu, Y.; Chen, Y. Org. Lett. 2019, 21, 3382.

(8) Luo, Z.; Liu, T.; Cheng, W.; Wu, K.; Xie, D.; Huo, L.; Sun, Y.; Yang, C. J. Mater. Chem. C 2018, 6, 1136.

(9) Hendsbee, A. D.; Sun, J.-P.; Law, W. K.; Yan, H.; Hill, I. G.; Spasyuk, D. M.; Welch, G. C. Chem. Mater. 2016, 28, 7098.

(10) Zhong, Y.; Trinh, M. T.; Chen, R.; Purdum, G. E.; Khlyabich, P. P.; Sezen, M.; Oh, S.; Zhu, H.; Fowler, B.; Zhang, B.; Wang, W.; Nam, C. Y.; Sfeir, M. Y.; Black, C. T.; Steigerwald, M. L.; Loo, Y. L.; Ng, F.; Zhu, X. Y.; Nuckolls, C. Nat. Commun. 2015, 6, 8242.

(11) Huang, T.; Chen, H.; Feng, J.; Zhang, A.; Jiang, W.; He, F.; Wang, Z. ACS Mater. Lett. 2019, 1, 404.

(12) Verreet, B.; Rand, B. P.; Cheyns, D.; Hadipour, A.; Aernouts, T.; Heremans, P.; Medina, A.; Claessens, C. G.; Torres, T. Adv. Energy Mater. 2011, 1, 565.

(13) Barth, W. E.; Lawton, R. G. J. Am. Chem. Soc. 1966, 88, 380.

(14) Nestoros, E.; Stuparu, M. C. Chem. Commun. 2018, 54, 6503.

(15) Chen, R.; Lu, R.-Q.; Shi, K.; Wu, F.; Fang, H.-X.; Niu, Z.-X.; Yan, X.-Y.; Luo, M.; Wang, X.-C.; Yang, C.-Y.; Wang, X.-Y.; Xu, B.; Xia, H.; Pei, J.; Cao, X.-Y. Chem. Commun. 2015, 51, 13768.

(16) Shi, K.; Lei, T.; Wang, X.-Y.; Wang, J.-Y.; Pei, J. Chem. Sci. 2014, 5, 1041.

(17) Lu, R.-Q.; Zhou, Y.-N.; Yan, X.-Y.; Shi, K.; Zheng, Y.-Q.; Luo, M.; Wang, X.-C.; Pei, J.; Xia, H.; Zoppi, L.; Baldridge, K. K.; Siegel, J. S.; Cao, X.-Y. Chem. Commun. 2015, 51, 1681.

(18) Mack, J.; Vogel, P.; Jones, D.; Kaval, N.; Sutton, A. Org. Biomol. Chem. 2007, 5, 2448.

(19) Valenti, G.; Bruno, C.; Rapino, S.; Fiorani, A.; Jackson, E. A.; Scott, L. T.; Paolucci, F.; Marcaccio, M.J. Phys. Chem. C 2010, 114, 19467.

(20) Li, J.; Terec, A.; Wang, Y.; Joshi, H.; Lu, Y.; Sun, H.; Stuparu, M. C.J. Am. Chem. Soc. 2017, 139, 3089.

(21) Anthony, J. E. Chem. Mater. 2011, 23, 583.

(22) Chen, R.; Lu, R.-Q.; Shi, P.-C.; Cao, X.-Y. Chin. Chem. Lett. 2016, 27, 1175.

(23) Rajeshkumar, V.; Marc, C.; Fichou, D.; Stuparu, M. C. Synlett 2016, 27, 2101.

(24) Deng, Y.; Xu, B.; Castro, E.; Fernandez-Delgado, O.; Echegoyen, L.; Baldridge, K. K.; Siegel, J. S. Eur. J. Org. Chem. 2017, 29, 4338.

(25) Lu, R. Q.; Zheng, Y. Q.; Zhou, Y. N.; Yan, X. Y.; Lei, T.; Shi, K.; Zhou, Y.; Pei, J.; Zoppi, L.; Baldridge, K. K.; Siegel, J. S.; Cao, X. Y.J. Mater. Chem. A 2014, 2, 20515.

(26) Shoyama, K.; Schmidt, D.; Mahl, M.; Würthner, F. Org. Lett. 2017, 19, 5328. 
(27) Renner, R.; Stolte, M.; Würthner, F. ChemistryOpen 2019, 9, 32.

(28) Shoyama, K.; Würthner, F. J. Am. Chem. Soc. 2019, 141, 13008.

(29) Gershberg, J.; Fennel, F.; Rehm, T. H.; Lochbrunner, S.; Würthner, F. Chem. Sci. 2016, 7, 1729.

(30) Cardona, C. M.; Li, W.; Kaifer, A. E.; Stockdale, D.; Bazan, G. C. Adv. Mater. 2011, 23, 2367.

(31) Organic solar cells were prepared by cleaning ITO substrates (Soluxx GmbH) with acetone (VWR, semiconductor grade), detergent, deionized water, and isopropanol (VWR, semiconductor grade) for $15 \mathrm{~min}$ each, followed by an ozone/UV treatment for $30 \mathrm{~min}$. The $\mathrm{ZnO}$ layer was deposited by spincoating $\mathrm{ZnO}$ nanoparticles on top of the substrates (3000 rpm, $30 \mathrm{~s})$ followed by an annealing step $\left(200^{\circ} \mathrm{C}, 1 \mathrm{~h}\right)$. The donoracceptor blends were prepared by stirring a $1: 1$ mixture with a total concentration of $15 \mathrm{mg} \mathrm{mL}^{-1}$ of donor (PCE-10 obtained from 1-Material Inc.; PM6 obtained from Brilliant Matters Inc.) and $\mathbf{4}$ in chlorobenzene for $3 \mathrm{~h}$ at room temperature under inert conditions followed by spin-coating at $1000 \mathrm{rpm}$ for $60 \mathrm{~s}$ (M. Braun Inertgas-Systeme $\mathrm{GmbH}$, UNIlab Pro, $c\left(\mathrm{O}_{2}\right)<1 \mathrm{ppm}, c$ $\left.\left(\mathrm{H}_{2} \mathrm{O}\right)<1 \mathrm{ppm}\right)$. The substrates were placed in the evaporation system (OPTIvap-XL, Creaphys $\mathrm{GmbH}$ ) and $\mathrm{MoO}_{3} d=10 \mathrm{~nm}$, $r=0.1 \AA \mathrm{s}^{-1}, p<10^{-6}$ mbar, rotation $\left.=10 \mathrm{rpm}\right)$ and aluminum ( $d=100 \mathrm{~nm}, \quad r=1-2 \AA \mathrm{s}^{-1}, p<10^{-6}$ mbar) were deposited on top of the active layer to obtain the inverted $\mathrm{BHJ}$ organic solar cells. The device area was $7.1 \mathrm{~mm}^{2}$. J-V characteristics were measured after calibration with a standard silicon solar cell with a KG filter (ISE Freiburg) under an AM1.5G Oriel Sol3ATM Class AAA solar simulator $\left(\right.$ Newport $^{\circledR}$ ) by a parameter analyzer (Botest Systems $\mathrm{GmbH}$ ). EQE measurements were carried out with a quantum efficiency/IPCE measurement kit $\left(\right.$ Newport $\left.^{\circledR}\right)$ by using a $300 \mathrm{~W}$ Xe lamp and a Cornerstone monochromator with a Merlin lock-in amplifier for detection. Thin-film UV/Vis spectra were measured on a Jasco V770 spectrometer using an integration sphere. AFM images were obtained by an NT-MDT Next Solver system in semi-contact mode by using a SCOUT 350 RAI (Nu Nano Ltd) silicon cantilever (spring constant $=42 \mathrm{~N} \mathrm{~m}^{-1}$; resonance frequency $=350 \mathrm{kHz}$ ).The high-resolution AFM image was measured at a AXS Multimode Nanoscope IV instrument in the tapping mode using a silicon cantilever from Olympus (OMCL-AC160TS) with a spring constant of $42 \mathrm{~N} \mathrm{~m}^{-1}$ and a resonance frequency of $300 \mathrm{kHz}$.

(32) Organic thin film transistors were fabricated on wafer substrates based on $\mathrm{Si} / \mathrm{SiO}_{2}(100 \mathrm{~nm}) /$ octadecyltriethoxysilane (OTES) with a capacitance of $32.4 \mathrm{nF} \mathrm{cm}{ }^{-2}$, which were rinsed prior to use with toluene (p.a. grade, VWR chemicals), acetone, and isopropanol (semiconductor grade, VLSI PURANAL ${ }^{\mathrm{TM}}$, Aldrich ${ }^{\circledR}$ Chemistry), successively. After drying under nitrogen flow, the substrates were placed into a nitrogen-filled glovebox (M. Braun Inertgas-Systeme $\mathrm{GmbH}$, UNIlab Pro, $c\left(\mathrm{O}_{2}\right)<1 \mathrm{ppm}, c$ $\left.\left(\mathrm{H}_{2} \mathrm{O}\right)<1 \mathrm{ppm}\right)$ and a freshly prepared solution of $\mathbf{4}\left(5 \mathrm{mg} \mathrm{mL}^{-1}\right.$ in chloroform) was spin-coated on top of the substrate $(1000 \mathrm{rpm}, 60 \mathrm{~s})$ followed by an annealing step $\left(100{ }^{\circ} \mathrm{C}\right.$, $5 \mathrm{Min}$ ). The substrates were placed into an evaporation system (OPTIvap-XL, Creaphys $\mathrm{GmbH}$ ) and gold was deposited on top of the organic layer through a shadow mask $(d=30 \mathrm{~nm}, r=0.2 \AA$ $\left.\mathrm{s}^{-1}, \quad p<10^{-6} \mathrm{mbar}\right)$. The resulting transfer and output characteristics were measured under inert conditions with an Agilent 4055C parameter analyzer and a Cascade EPS150 probe station $(W=1000 \mu \mathrm{m}, L=20 \mu \mathrm{m})$.

(33) Würthner, F.; Meerholz, K. Chemistry 2010, 16, 9366. 